\title{
Anxiety and depression are common in rheumatoid arthritis and correlate with poor quality of life in Indian patients
}

\author{
Gurmeet Singh 10 , Nikhil Mahajan, Sameer Abrol, Abhinav Raina \\ Department of Medicine, Government Medical College, Jammu and Kashmir, India
}

\begin{abstract}
Objectives: We planned this study to assess the prevalence of anxiety and depression in rheumatoid arthritis (RA) patients and its correlation with quality of life (QOL) in these patients.

Material and methods: Eighty-eight patients (76 females) were included in this cross-sectional study. The Hospital Anxiety and Depression Scale (HADS) was used to assess anxiety and depression. Quality of life was measured using the World Health Organization WHOQOL-BREF. The severity of pain was measured by 100-millimetre-long Visual Analogue Scale (VAS), and functional disability was measured by using the Indian version of the Health Assessment Questionnaire (HAQ). The disease activity was measured by Disease Activity Score for 28 joints with 3 variables.

Results: Probable anxiety and depression were seen in 61 (69\%) and $68(77 \%)$ of the patients, respectively. Patients with anxiety had more severe pain (VAS $53.8 \pm 26.4$ vs. $39.7 \pm 26.1, p<0.05$ ), and significantly lower scores in all the 4 domains of the WHOQOL-BREF. Patients with depression had more pain (VAS $54.2 \pm 25.2$ vs. $33.5 \pm 27.3, p<0.01$ ), higher HAQ scores (1.0 \pm 0.7 vs. $0.5 \pm 0.7$, $p<0.01$ ), and lower QOL scores. Both anxiety and depression scores had a negative correlation with all the 4 domains of the WHOQOL-BREF. Anxiety had a significant negative effect on psychological $(\beta=-0.58, p<0.001)$ and environmental domains $(\beta=-0.39, p<0.001)$, while depression had a significant negative effect on psychological $(\beta=-0.57, p<0.001)$ and environmental domains $(\beta=-0.53, p<0.001)$. Both anxiety and depression predicted more pain in RA patients $(\beta=0.24, p<0.001$ and $\beta=0.44, p<0.001$, respectively).

Conclusions: Anxiety and depression correlated with poor QOL in all 4 domains of the WHOQOL-BREF. Higher HADS scores had a negative effect on all the domains of the WHOQOL-BREF and predicted more severe pain in RA patients. Thus, patients with RA need to be screened and treated for underlying anxiety and depression to improve their QOL, pain, and functional status.
\end{abstract}

Key words: quality of life, rheumatoid arthritis, depression, pain, anxiety.

\section{Introduction}

Rheumatoid arthritis (RA) is a chronic inflammatory disorder having a major manifestation as peripheral arthritis, but also with systemic manifestations. The focus of the treating physicians is to control the disease activity using disease modifying agents and biologicals with little emphasis on addressing the underlying psychiatric morbidity.

Various studies have shown the prevalence of depression and anxiety in RA patients to be as low as $6 \%$ and $2.5 \%$ to as high as $66 \%$ and $70 \%$, respectively [ $1-4]$. Studies using the Hospital Anxiety and Depression Scale (HADS) revealed a lower prevalence of anxiety and depression [1-3], while the study using Research Diagnostic Criteria for the International Classification of Diseases-10 (ICD-10) showed a higher prevalence of anxiety and depression [4].

A study from India reported the prevalence of anxiety and depression to be $25 \%$ and $17 \%$, respectively, of RA patients using HADS [5]. Also, there are studies reporting lower prevalence of anxiety and depression from South East Asia, while a study from Egypt reported a higher prevalence [1-5].

Address for correspondence:

Gurmeet Singh, Department of Medicine, Government Medical College, Jammu - 180 001, Jammu and Kashmir, India, e-mail: gurmeet06@gmail.com

Submitted: 22.05.2021; Accepted: 27.11.2021 
The prevalence of depression amongst the general population in India was found to be $2.6 \%$ and $15.1 \%$ in 2 different studies $[6,7]$. The prevalence of anxiety in a systematic review was found to be between $0.9 \%$ and $28.3 \%$ in 87 studies across 44 countries [8]. The prevalence of anxiety in India was found to be around 1.6\% [9]

Both anxiety and depression affect the patients' perception of their current health status [2]. Patients with anxiety and depression may have inflated disease activity scores (DAS) by providing increased swollen and tender joint counts in the absence of active disease, thus complicating the management of the disease. The effect may be due to increased pain perception in these patients leading to higher TJC and patient global assessment [10].

Anxiety and depression have a negative impact on quality (QOL) of life in RA, and identification and treatment of underlying psychiatric morbidity is essential to improve the QOL in these patients [11].

Patients with higher scores of depression have more intense pain, poor compliance with the treatment, worse prognosis, and poor QOL, and the presence of depression should alert the treating physician to treat depression and prevent these factors [12].

Anxiety and depression have a significant effect on the QOL in RA patients, which has been shown in multiple studies. We undertook this study to look at the prevalence of anxiety and depression in RA and its correlation with quality of life, pain, disease activity, and functional status in these patients because there are no studies from India about this topic at present.

\section{Material and methods}

The study was conducted in a tertiary care teaching hospital in North India. Patients with disease duration of more than 1 year as per 2010 American College of Rheumatology/European League Against Rheumatism criteria were included in the study [13].

Patients already on antidepressants and anxiolytics were excluded. Quality of life was assessed by using the World Health Organization Quality of Life (WHOQOL-BREF) Hindi version, which is a patient-administered 26-item questionnaire [14].

The questionnaire assesses the scores in four domains, i.e. physical, psychological, social relationships, and environment, with higher scores (transformed to 0-100) reflecting better QOL. Illiterate patients were assisted by the interviewer to complete the questionnaire. Anxiety and depression were measured by using HADS, which is a 14-item questionnaires with 7 responses each for anxiety and depression with a maximum possible score of 3 for a particular response. A score of up to 7 is considered normal, with scores of 8-10 as borderline abnormal and scores 11-21 as being abnormal [15].
Higher scores indicate more severe anxiety and depression. Pain was measured by 100-millimetre Visual Analogue Scale (VAS). The disease activity was measured by Disease Activity Score for 28 joints with 3 variables (DAS28-3) i.e. swollen joint count, tender joint count (TJC), and erythrocyte sedimentation rate by Westergren's method [16].

Swollen and tender joints were assessed by 1 examiner (GS). Functional disability was measured by using the Indian version of the Health Assessment Questionnaire (HAQ), with higher scores indicating more disability [17].

The physical health domain covers activities of daily living, mobility, pain, discomfort sleep, rest, and work capacity. It includes questions such as:

- Do you have enough energy for everyday life?

- How well are you able to get around?

- How satisfied are you with your ability to perform your daily living activities?

The psychological domain covers body image and appearance, negative feelings, positive feelings, and self-esteem with questions such as:

- How much do you enjoy life?

- To what extent do you feel your life to be meaningful?

- Are you able to accept your bodily appearance?

- How satisfied are you with yourself?

- How often do you have negative feelings such as blue mood, despair, anxiety, or depression?

The social domain includes personal relationships, social support, and sexual activity with questions such as:

- How satisfied are you with your personal relationships?

- How satisfied are you with your sex life?

- How satisfied are you with the support you get from your friends?

And the environmental domain covers financial resources freedom, physical safety and security, health and social care: accessibility and quality, home environment, participation in and opportunities for recreation/leisure activities, and transport. The questions in this domain include:

- How safe do you feel in your daily life?

- How healthy is your physical environment?

- Do you have enough money to meet your needs?

- To what extent do you have the opportunity for leisure activities?

- How satisfied are you with your access to health services?

- How satisfied are you with your transport? [14].

The study protocol was approved by the Institution Ethics Committee. IEC/Pharma/Thesis/Research/Project/09/2011/2060/Category-C. All the patients gave written informed consent.

\section{Statistical analysis}

Data were analysed using OpenStat software. The normality of the data was assessed by the Shapiro-Wilk 
Table I. Characteristics of the rheumatoid arthritis patients $(N=88)$

\begin{tabular}{|c|c|}
\hline Variable & Parameters \\
\hline Age [years, mean \pm SD (range)] & $47.7 \pm 14.6(21-84)$ \\
\hline Females $[n(\%)]$ & $76(86)$ \\
\hline $\begin{array}{l}\text { Disease duration } \\
\text { [years, mean } \pm S D \text { (range)] }\end{array}$ & $6.9 \pm 8.4(0.7-61)$ \\
\hline $\begin{array}{l}\text { Tender joint count } \\
\text { [mean } \pm \text { SD (range)] }\end{array}$ & $6.0 \pm 7.0(0-26)$ \\
\hline $\begin{array}{l}\text { Swollen joint count } \\
\text { [mean } \pm \text { SD (range)] }\end{array}$ & $3.4 \pm 3.9(0-20)$ \\
\hline $\begin{array}{l}\text { ESR }\left(\mathrm{mm} \mathrm{1} 1^{\text {st }} \mathrm{hr}\right) \\
{[\text { mean } \pm S D(\text { range })]}\end{array}$ & $66.2 \pm 40.7(10-170)$ \\
\hline DAS28-3 [mean \pm SD (range)] & $4.6 \pm 1.3(2.1-7.8)$ \\
\hline $\mathrm{HAQ}[$ mean $\pm \mathrm{SD}$ (range)] & $0.9 \pm 0.7(0-2.9)$ \\
\hline Pain (VAS) [mean $\pm S D$ (range)] & $49.5 \pm 7.0(8-98)$ \\
\hline $\begin{array}{l}\text { Anxiety score } \\
{[\text { mean } \pm S D(\text { range })]}\end{array}$ & $10.0 \pm 4.5(0-19)$ \\
\hline $\begin{array}{l}\text { Depression score } \\
{[\text { mean } \pm S D \text { (range) }]}\end{array}$ & $9.5 \pm 3.9(0-19)$ \\
\hline $\begin{array}{l}\text { Psychological } \\
{[\text { mean } \pm S D \text { (range)] }}\end{array}$ & $39.8 \pm 17.1(0-81)$ \\
\hline $\begin{array}{l}\text { Psychological } \\
{[\text { mean } \pm S D(\text { range) }]}\end{array}$ & $42.3 \pm 18.8(0-88)$ \\
\hline Social [mean \pm SD (range)] & $53.3 \pm 22.3(0-94)$ \\
\hline $\begin{array}{l}\text { Environmental } \\
\text { [mean } \pm S D \text { (range)] }\end{array}$ & $49.5 \pm 17.3(13-81)$ \\
\hline
\end{tabular}

DAS28-3 - Disease Activity Score, ESR - erythrocyte sedimentation rate, $H A Q$ - Health Assessment Questionnaire, SD - standard deviation, VAS - Visual Analogue Scale.

test. Student's t-test was used to analyse the normally distributed continuous variables, and the Wilcoxon sign rank-test was used for variables not normally distributed, i.e. disease duration, HAQ, pain, and social and environmental domains of the WHOQOL-BREF. The $\chi^{2}$ test was used to test for discrete variables. A $p$-value of $<0.05$ was considered significant.

Correlations were calculated between anxiety, depression, and domains of the WHOQOL, DAS28-3, $\mathrm{HAQ}$, pain (VAS), and disease duration. For correlations a $p$-value $<0.01$ was considered significant in view of multiple comparisons. The effect of anxiety and depression on QOL domains, pain (VAS), HAQ, and DAS28-3 was measured by linear regression analysis. Anxiety and depression were taken as independent variables while QOL domains, pain (VAS), HAQ, and DAS28-3 were taken as dependent variables. The higher values of $\beta$ coefficient suggesting the stronger the effect of independent variables on the dependent variables.

\section{Results}

A total of 88 patients were enrolled into the study, of whom 76 were female. The mean age of the patients was $47.7 \pm 14.6$ years, and mean disease duration was $6.9 \pm 8.4$ years. None of the investigated patients were treated with biological drugs. Baseline characteristics of the patients are shown in the Table I.

Possible anxiety and depression with a HADS score of > 7 was seen in 61 (69\%) and 68 (77\%) of the patients, respectively (Table $\mathrm{II}, \mathrm{III})$.

There were no significant differences between RA patients with anxiety compared in terms of age and DAS28-3 with patients without anxiety. Although female patients were more likely to report anxiety (Table II).

Patients with anxiety were likely to have a shorter disease duration ( $6.6 \pm 6.4$ vs. $7.8 \pm 11.9$ years, $p<0.0001)$, higher HAQ scores $(0.9 \pm 0.7$ vs. $0.7 \pm 0.8, p<0.001)$, higher pain level (VAS $53.8 \pm 26.4$ vs. $39.7 \pm 26.1, p<0.05$ ) and more often had depression (95\% vs. $37 \%, p<0.0001$ ) compared to patients without anxiety. Patients with anx-

Table II. Comparison of rheumatoid arthritis patients with and without anxiety $(N=88)$

\begin{tabular}{|c|c|c|c|}
\hline Variable & Anxiety $(n=61)$ & No anxiety $(n=27)$ & $p$-value \\
\hline Age [years, mean \pm SD] & $47.0 \pm 13.9$ & $49.4 \pm 16.3$ & NS \\
\hline Females $[n(\%)]$ & $56(91)$ & $20(74)$ & $<0.05$ \\
\hline Disease duration [years, mean $\pm \mathrm{SD}$ ] & $6.6 \pm 6.4$ & $7.8 \pm 11.9$ & $<0.0001$ \\
\hline DAS28-3 as in methods section [mean \pm SD] & $4.5 \pm 1.3$ & $4.8 \pm 1.2$ & NS \\
\hline $\mathrm{HAQ}[$ mean $\pm \mathrm{SD}]$ & $0.9 \pm 0.7$ & $0.77 \pm 0.8$ & $<0.001$ \\
\hline Pain (VAS) [mean \pm SD] & $53.8 \pm 26.4$ & $39.7 \pm 26.1$ & $<0.0001$ \\
\hline Depression [\%] & $58(95)$ & $10(37)$ & $<0.0001$ \\
\hline Physical health [mean \pm SD] & $36.3 \pm 13.9$ & $47.8 \pm 20.8$ & $<0.01$ \\
\hline Psychological [mean \pm SD] & $36.0 \pm 16.4$ & $56.5 \pm 16.1$ & $<0.001$ \\
\hline Social $[$ mean \pm SD] & $48.4 \pm 23.6$ & $64.5 \pm 13.9$ & $<0.0001$ \\
\hline Environmental [mean \pm SD] & $45.3 \pm 16.4$ & $59.1 \pm 15.6$ & $<0.0001$ \\
\hline
\end{tabular}

DAS28-3 - Disease Activity Score, HAQ - Health Assessment Questionnaire, NS - not significant, SD - standard deviation, VAS-Visual Analogue Scale. 
Table III. Comparison of rheumatoid arthritis patients with and without depression $(N=88)$

\begin{tabular}{|lccc|}
\hline Variable & Depression $(n=68)$ & No depression $(n=20)$ & $p$-value \\
\hline Age [years, mean \pm SD] & $47.5 \pm 13.9$ & $48.6 \pm 17.1$ & NS \\
\hline Females $[n(\%)]$ & $60(88)$ & $16(80)$ & NS \\
\hline Disease duration [years, mean \pm SD] & $7.7 \pm 9.3$ & $4.34 \pm 2.8$ & NS \\
\hline DAS28-3 & $4.6 \pm 1.4$ & $4.7 \pm 1.0$ & $<0.01$ \\
\hline HAQ [mean $\pm S D]$ & $1.0 \pm 0.7$ & $0.5 \pm 0.7$ & $<0.001$ \\
\hline Pain $($ VAS) $[$ mean $\pm S D]$ & $54.2 \pm 25.2$ & $33.5 \pm 27.3$ & $<0.0001$ \\
\hline Anxiety $[n(\%)]$ & $58(85)$ & $3(15)$ & $<0.01$ \\
\hline Physical health [mean $\pm S D]$ & $37.2 \pm 15.9$ & $48.9 \pm 18.1$ & $<0.001$ \\
\hline Psychological [mean $\pm S D]$ & $38.6 \pm 17.1$ & $55.1 \pm 19.2$ & $<0.001$ \\
\hline Social [mean \pm SD] & $48.9 \pm 22.9$ & $68.4 \pm 11.1$ & $<0.001$ \\
\hline Environmental [mean $\pm S D]$ & $46.3 \pm 16.9$ & $60.4 \pm 14.3$ & \\
\hline
\end{tabular}

DAS28-3 - Disease Activity Score, HAQ - Health Assessment Questionnaire, NS - not significant, SD - standard deviation, VAS - Visual Analogue Scale.

iety had significantly lower scores in all 4 domains of the WHOQOL-BREF as compared to patients without anxiety, suggesting poor QOL for patients with anxiety (Table II).

\section{Comparison of rheumatoid arthritis patients with and without depression}

There was no significant difference in the age, gender, and DAS28-3 between the patients in the "depression" and "no depression" groups. Patients in the "depression" group had longer disease duration (7.7 \pm 9.3 vs. $4.34 \pm 2.8$ years, $p<0.001)$ and higher HAQ scores (1.0 \pm 0.7 vs. $0.5 \pm 0.7, p<0.01)$ as compared to patients in the "no depression" group, suggesting more disability in depressed patients.

Patients in the "depression" group also had higher pain level (VAS $54.2 \pm 25.2$ vs. $33.5 \pm 27.3, p<0.01$ ) and were more likely to have anxiety ( $85 \%$ vs. $15 \%, p<0.0001)$ (Table III). Quality of life scores of the patients in the "depression" group were significantly lower than the patients in the "no depression" group (Table III).

\section{Correlations between anxiety and depression scores and World Health Organization quality of life domains}

The anxiety score had a negative correlation with all 4 domains of the WHOQOL-BREF, with the psychological health domain showing a strong negative correlation with the anxiety score $(r=-0.55, p<0.0001)$ (Fig. 1).

Similarly, the depression score had a negative correlation with all the domains, with the psychological $(r=-0.55, p<0.001)$ and environment $(r=-0.53$, $p<0.001)$ domains showing strong negative correlation with depression scores (Fig. 2).

\section{Correlations between anxiety, depression scores and Disease Activity Score, Health Assessment Questionnaire, pain and disease duration}

No significant correlation was found between anxiety scores and DAS28-3 ( $r=-0.04, p=$ NS [not significant]), HAQ $(r=0.20, p=\mathrm{NS})$, pain (VAS) $(r=0.24, p=\mathrm{NS})$, and disease duration ( $r=-0.06, p=N S)$. A significant positive correlation was found between depression score and disease duration $(r=0.30, p<0.01)$, while no significant correlation was found between depression scores and DAS28-3 ( $r=0.07, p=\mathrm{NS})$, HAQ $(r=0.13$, $p=\mathrm{NS})$, and pain (VAS) $(r=0.12, p=\mathrm{NS})$.

\section{Effects of anxiety and depression on quality of life and pain, Health \\ Assessment Questionnaire, Disease Activity Score and disease duration}

On linear regression analysis anxiety had a significant effect on physical $(\beta=-0.38, p<0.001)$, psychological $(\beta=-0.58, p<0.001)$, social $(\beta=-0.36, p<0.001)$, and environmental domains $(\beta=-0.39, p<0.001)$ and pain scores $(\beta=0.248, p<0.05)$. No effect was seen on HAQ, DAS28-3 (Table IV).

Depression also had a significant effect on all the domains of the WHOQOL-BREF as well as pain $(\beta=0.44$, 

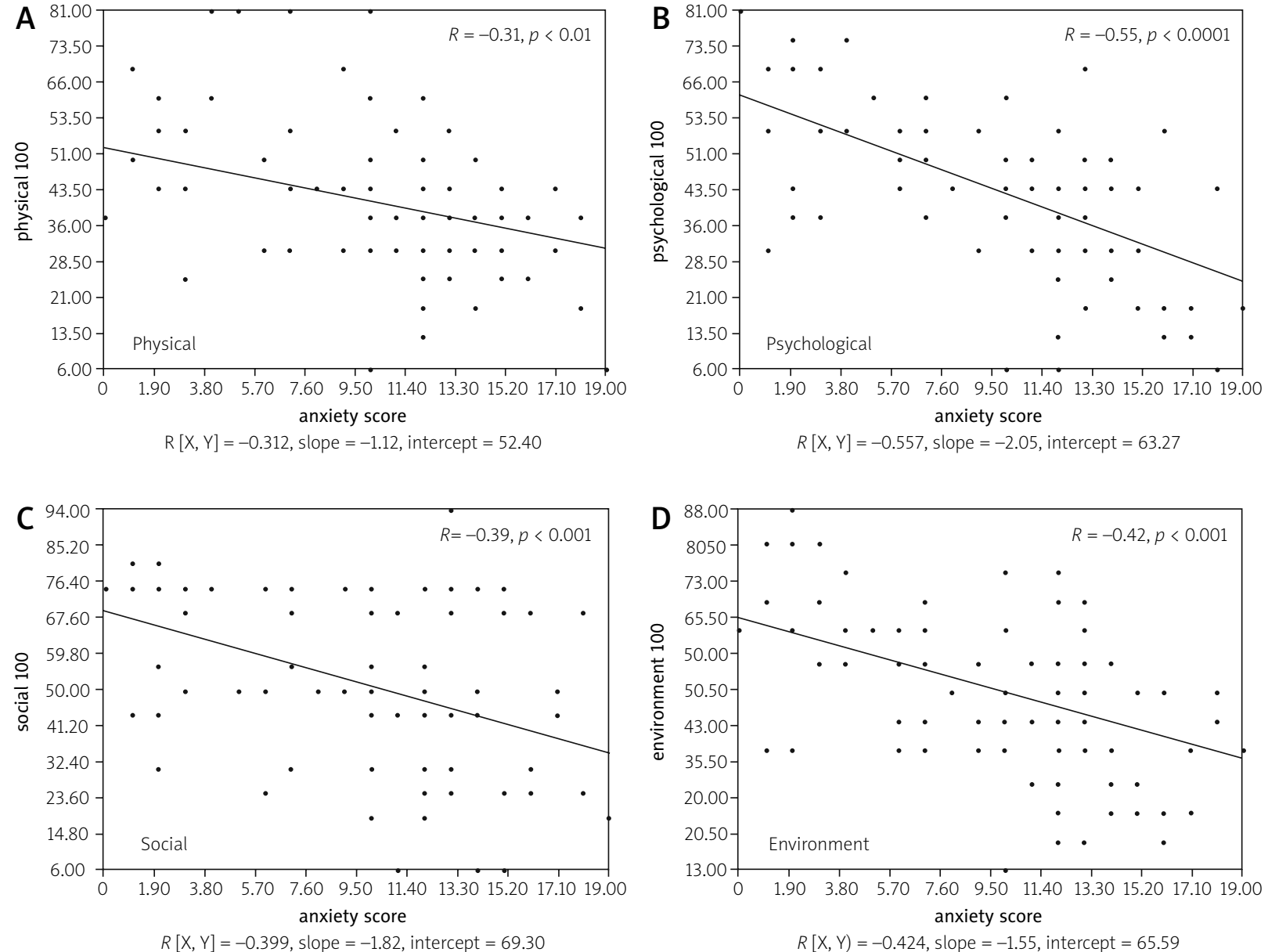

Fig. 1. Correlations between anxiety scores and quality of life domains.

$p<0.001)$, HAQ $(\beta=0.47, p<0.001)$, and DAS28-3 $(\beta=0.22, p<0.05)$.

\section{Discussion}

In patients with RA the main objective of the treating physicians is improvement in the disease activity parameters measured by various scores such as DAS28-3 or American College of Rheumatology improvement criteria [18].

Underlying mood disorders in the form of anxiety and depression may be the reason for persistent pain despite the control of disease activity with drugs. Diagnosis of the underlying mood disorder and its treatment may be necessary for the control of pain and improvement in the QOL of the patient [19]. Because there is a relationship between severity of depression and disease activity, treatment of depression may lead to improvement in the care of RA patients [20].

About three-fourths of the patients had HADS score $>7$, suggesting the presence of possible depression and anxiety in our study. Although this appears to be a high number, similar results have been seen in other studies.
The reason for a high prevalence in our study could be the use of HADS as an instrument where a score of more than 7 is taken as a cut-off for abnormal results.

Another reason could be lack of social support in our patients, who were predominantly females (86\%).

A study from Egypt reported a high prevalence of anxiety (70\%) and depression (66.2\%) in RA patients using Research Diagnostic Criteria for the ICD-10 [4]. Depression was associated with functional disability, social stress, and morning stiffness. Anxiety was associated with depression in these patients [4].

An Iranian study reported the presence of depression in $63 \%$ and anxiety in $84 \%$ of RA patients. Both anxiety and depression were associated with higher pain perception and increased functional disability [21].

Around $62 \%$ and $60 \%$ of patients had depression and anxiety, respectively, in a Chinese study that used the Hamilton Depression Scale and Hamilton Anxiety Scale. Both anxiety and depression were associated with higher disease activity [22].

A study from India in fibromyalgia patients also reported high levels of anxiety (87\%) and depression 

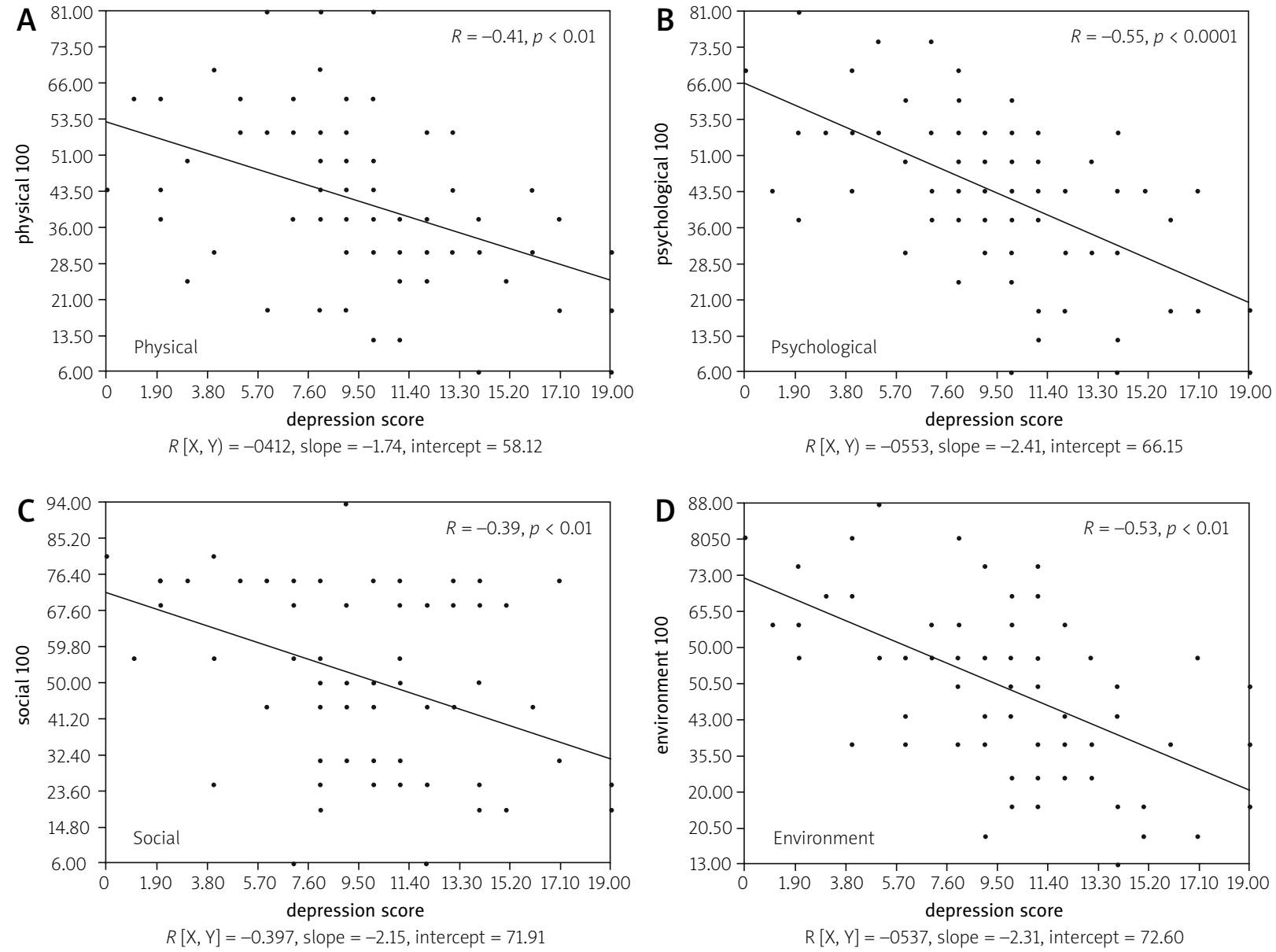

Fig. 2. Correlations between depression scores and quality of life domains.

(72\%), and patients with anxiety and depression had poor QOL, more pain, and disturbed sleep [23]. We found that depression besides affecting all the domains of QOL significantly affected pain, functional status and disease activity in our patients. This has been seen in multiple previous studies [4, 19-22].

Depression affects the RA patient in multiple ways. Patients with underlying depression are more likely to have poor QOL, poor compliance with medications, decreased pain threshold, and increase pain perception. Depression in RA is also associated with poor sleep and fatigue, increased risk of suicide, and increased risk of death [24].

Also, patients with depression tend to have poor functional status, and any improvement in depression may lead to improvement in the functional status of the patient [25]. A Dutch study revealed that the fluctuations in the level of depression were associated with the fluctuating levels of functional status of RA patients [26]. Anxiety is usually a known accompaniment of depression and poses diagnostic and therapeutic challenges [27, 28].

In our study anxiety was also found to be a significant co-morbidity in RA patients, and it was more likely to be found in females. Patients with anxiety were more likely to be depressed and had more pain. Both anxiety and depression had significant negative correlation with all the domains of the WHOQOL-BREF, i.e. physical health, psychological, social relationships, and environmental domains.

Studies have shown that anxiety and depression when present in RA patients may lead to poor QOL, increased risk of suicide, and poor prognosis of the disease [29]. The relationship between depression and RA appears to be bidirectional, and the clinical guidelines suggest diagnosing and managing mental health and depression in chronic medical conditions like RA to improve treatment outcomes [20].

Mood disorders in the form of anxiety and depression are quite common in RA patients [1-4]. Usually the treating physicians or rheumatologists are focused on treating arthritis and achieving low DAS28-3 scores. This pushes the underlying mood disturbances into the background.

In a study from Pakistan the diagnosis of clinical depression was missed in $47 \%$ of patients with RA who had been under regular follow-up at a tertiary care hospital. Only $18 \%$ of those diagnosed with depression were 
Table IV. Linear regression analysis for effect of anxiety and depression on quality of life domains, pain, Health Assessment Questionnaire, Disease Activity Scores

\begin{tabular}{|lccccc|}
\hline & B & SE & $\beta$ & $t$ & $p$-value \\
\hline Anxiety & & & & & \\
\hline Physical & -1.427 & 0.373 & -0.382 & -3.830 & $<0.001$ \\
\hline Psychological & -2.409 & 0.360 & -0.585 & -6.698 & $<0.001$ \\
\hline Social & -1.795 & 0.490 & -0.367 & -3.661 & $<0.001$ \\
\hline Environmental & -1.512 & 0.375 & -0.399 & -4.030 & $<0.001$ \\
\hline Pain (VAS) & 1.424 & 0.599 & 0.248 & 2.376 & $<0.05$ \\
\hline HAQ & 0.033 & 0.017 & 0.201 & 1.900 & 0.061 \\
\hline DAS28-3 & -0.012 & 0.031 & -0.042 & -0.392 & 0.696 \\
\hline Depression & & & & & \\
\hline Physical & -1.859 & 0.417 & -0.433 & -4.457 & $<0.001$ \\
\hline Psychological & -2.701 & 0.418 & -0.572 & -6.463 & $<0.001$ \\
\hline Social & -2.742 & 0.528 & -0.489 & -5.196 & $<0.001$ \\
\hline Environmental & -2.331 & 0.397 & 0.535 & -5.877 & $<0.001$ \\
\hline Pain (VAS) & 2.956 & 0.634 & 0.449 & 4.659 & $<0.001$ \\
\hline HAQ & 0.089 & 0.018 & 0.476 & 5.025 & $<0.001$ \\
\hline DAS28-3 & 0.074 & 0.035 & 0.223 & 2.117 & $<0.05$ \\
\hline
\end{tabular}

$B$ - unstandardised regression coefficients, $\beta$-standardised regression coefficients, DAS28-3 - Disease Activity Score, HAQ - Health Assessment Questionnaire, NS - not significant, SE - standard error of the unstandardised coefficient, VAS - Visual Analogue Scale. Anxiety and depression assessed by Hospital Anxiety and Depression Scale with scores > 7 seen as abnorm.

willing to seek referral to a psychiatrist for management of depression [30].

The undiagnosed anxiety and depression may lead to less than satisfactory outcomes even when the joint disease is satisfactorily controlled with drugs [10, 21]. Patients with depression or anxiety may still complain of pain despite having good control of synovitis [19, 20].

Because all the patients visiting the rheumatology clinic are assessed for disease activity and extraarticular manifestations at each visit, they need to be assessed for underlying psychiatric morbidity. Because most of the questionnaires for anxiety and depression are self-assessment questionnaires, these can be handed over to the patients in the waiting areas and the scores noted down in the patients records so that any change in the mood disorder be picked up and the patient be referred to mental health specialists for confirmation of the diagnosis and further management.

The Hospital Anxiety and Depression Scale is a self-assessment questionnaire that serves only as a screening tool for anxiety and depression, and the definite diagnosis depends upon clinical assessment of the patient. With a cut-off of 7, a score of 8-10 is suggestive of an underlying mood disorder, and a score of 11 or more suggests probable presence of mood disorders [31].

\section{Study limitations}

Our study also had some limitations. There was no control group to compare the prevalence of anxiety and depression of our patients with the normal population. As this is a cross sectional study, we were only able to capture the data at a single time point in the disease process of the patient.

Studied patients were recruited from the outpatient department of a tertiary care center, which usually takes care of patients with higher disease activity. In the presented analysis a mean DAS28-3 score was $4.6 \pm 1.3$ range (2.1-7.8), which suggests that most of the patients had a moderate activity of the disease (DAS28-3 score between 3.2 to $\leq 5.1$ ) [32]. It means that this sample of the patients may not be representative for all the patients with RA seen in primary and secondary care.

\section{Conclusions}

In our study, we found a high prevalence of probable anxiety and depression in RA patients. Higher anxiety scores were associated with more intense pain and lower QOL in all the domains. Higher depression scores were associated with more pain, anxiety, poor functional status, and lower QOL in all the domains.

Both anxiety and depression scores had a negative correlation with all the domains of the WHOQOL-BREF. Both anxiety and depression had negative effects on psychological and environmental domains, and pain in RA patients.

Mood disorders in the form of anxiety and depression are common in RA patients and these have an impact on multiple parameters of the disease like pain, disease activity, QOL, and functional status of the patients. The assessment of the mental health of RA patients should be included in the routine assessment of the patients similar to the assessment of DAS28-3 at each visit. There is important that any changes in mental health could have been detected earlier and the patient will have a possibility to be assessed by a psychiatrist for establishing the diagnosis and further management.

The authors declare no conflict of interest.

\section{References}

1. Ng KJ, Huang $\mathrm{KY}$, Tung $\mathrm{CH}$, et al. Risk factors, including different biologics, associated with depression and anxiety in patients with rheumatoid arthritis: a cross-sectional observational study. Clin Rheumatol 2020; 39: 737-746, DOI: 10.1007/s10067-019-04820-x. 
2. Katchamart W, Narongroeknawin P, Chanapai W, et al. Prevalence of and factors associated with depression and anxiety in patients with rheumatoid arthritis: a multicenter prospective cross-sectional study. Int J Rheum Dis 2020; 23: 302-308, DOI: 10.1111/1756-185X.13781.

3. Ho RC, Fu EH, Chua AN, et al. Clinical and psychosocial factors associated with depression and anxiety in Singaporean patients with rheumatoid arthritis. Int J Rheum Dis 2011; 14: 37-47, DOI: 10.1111/j.1756-185X.2010.01591.x.

4. El-Miedany $\mathrm{YM}$, el-Rasheed $\mathrm{AH}$. Is anxiety a more common disorder than depression in rheumatoid arthritis? Joint Bone Spine 2002; 69: 300-306, DOI: 10.1016/s1297319x(02)00368-8.

5. Dhir V, Lawrence A, Aggarwal A, Misra R. Fibromyalgia is common and adversely affects pain and fatigue perception in North Indian patients with rheumatoid arthritis. J Rheumatol 2009; 36: 2443-2448, DOI: 10.3899/jrheum.090157.

6. Arvind BA, Gururaj G, Loganathan S, et al. Prevalence and socioeconomic impact of depressive disorders in India: multisite population-based cross-sectional study. BMJ Open 2019; 27; 9: e027250, DOI: 10.1136/bmjopen-2018-027250.

7. Poongothai S, Pradeepa R, Ganesan A, Mohan V. Prevalence of depression in a large urban South Indian population - the Chennai Urban Rural Epidemiology Study (CURES-70). PLoS One 2009; 28; 4: e7185, DOI: 10.1371/journal.pone.0007185.

8. Baxter AJ, Scott KM, Vos T, Whiteford HA. Global prevalence of anxiety disorders: a systematic review and metaregression. Psychol Med 2013; 43: 897-910, DOI: 10.1017/ S003329171200147X

9. Ganguli HC. Epidemiological findings on prevalence of mental disorders in India. Indian J Psychiatry 2000; 42: 14-20.

10. Matcham F, Ali S, Irving K, et al. Are depression and anxiety associated with disease activity in rheumatoid arthritis? A prospective study. BMC Musculoskelet Disord 2016; 17: 155, DOI: 10.1186/s12891-016-1011-1

11. Hattori Y, Katayama M, Kida D, Kaneko A. Hospital Anxiety and Depression Scale Score is an independent factor associated with the EuroQoL 5-Dimensional Descriptive System in patients with rheumatoid arthritis. J Clin Rheumatol 2018; 24 : 308-312, DOI: 10.1097/RHU.0000000000000735.

12. Pinho de Oliveira Ribeiro N, Rafael de Mello Schier A, Ornelas AC, et al. Anxiety, depression and suicidal ideation in patients with rheumatoid arthritis in use of methotrexate, hydroxychloroquine, leflunomide and biological drugs. Compr Psychiatry 2013; 54: 1185-1189, DOI: 10.1016/j.comppsych.2013.05.010.

13. Aletaha D, Neogi T, Silman AJ, et al. 2010 Rheumatoid arthritis classification criteria: an American College of Rheumatology/ European League Against Rheumatism collaborative initiative. Arthritis Rheum 2010; 62: 2569-2581, DOI: 10.1002/art.27584.

14. Saxena S, Chandiramani K, Bhargava R. WHOQOL-Hindi: a questionnaire for assessing quality of life in health care settings in India. World Health Organization Quality of Life. Natl Med J India 1998; 11: 160-165.

15. Zigmond AS, Snaith RP. The hospital anxiety and depression scale. Acta Psychiatr Scand 1983; 67: 361-370.

16. Van der Heijde DM, van 't Hof M, van Riel PL, van de Putte LB. Development of a disease activity score based on judgment in clinical practice by rheumatologists. J Rheumatol 1993; 20: 579-581.
17. Kumar A, Malaviya AN, Pandhi A, Singh R. Validation of an Indian version of the Health Assessment Questionnaire in patients with rheumatoid arthritis. Rheumatology (Oxford) 2002; 41: 1457-1459.

18. American College of Rheumatology Committee to Reevaluate Improvement Criteria. A proposed revision to the ACR20: the hybrid measure of American College of Rheumatology response. Arthritis Rheum 2007; 57: 193-202, DOI: 10.1002/art.22552.

19. Chancay MG, Guendsechadze SN, Blanco I. Types of pain and their psychosocial impact in women with rheumatoid arthritis. Womens Midlife Health 2019; 5: 3, DOI: 10.1186/s40695-0190047-4.

20. Lwin MN, Serhal L, Holroyd C, Edwards CJ. Rheumatoid arthritis: the impact of mental health on disease: a narrative review. Rheumatol Ther 2020; 7: 457-471, DOI: 10.1007/s40744-020-00217-4.

21. Jamshidi AR, Banihashemi AT, Paragomi P, et al. Anxiety and depression in rheumatoid arthritis: an epidemiologic survey and investigation of clinical correlates in Iranian population. Rheumatol Int 2016; 36: 1119-11125, DOI: 10.1007/s00296-016-3493-4.

22. Pu D, Luo J, Wang Y, et al. Prevalence of depression and anxiety in rheumatoid arthritis patients and their associations with serum vitamin D level. Clin Rheumatol 2018; 37: 179-184, DOI: 10.1007/s10067-017-3874-4.

23. Singh G, Kaul S. Anxiety and depression are common in fibromyalgia patients and correlate with symptom severity score. Indian J Rheumatol 2018; 13: 168-172.

24. Withers MH, Gonzalez LT, Karpouzas GA. Identification and treatment optimization of comorbid depression in rheumatoid arthritis. Rheumatol Ther 2017; 4: 281-291, DOI: 10.1007/ s40744-017-0072-4

25. Karpouzas GA, Draper T, Moran R, et al. Trends in functional disability and determinants of clinically meaningful change over time in hispanic patients with rheumatoid arthritis in the US. Arthritis Care Res (Hoboken) 2017; 69: 294-298, DOI: 10.1002/acr.22924.

26. Doeglas DM, Suurmeijer TP, van den Heuvel WJ, et al. Functional ability, social support, and depression in rheumatoid arthritis. Qual Life Res 2004; 13: 1053-1065, DOI: 10.1023/B: QURE.0000031339.04589.63.

27. Zajecka JM, Ross JS. Management of comorbid anxiety and depression. J Clin Psychiatry 1995; 56 (Suppl 2): 10-13.

28. Lydiard RB, Brawman-Mintzer O. Anxious depression. J Clin Psychiatry 1998; 59 (Suppl 18): 10-17.

29. Beşirli A, Alptekin JÖ, Kaymak D, Özer ÖA. The relationship between anxiety, depression, suicidal ideation and quality of life in patients with rheumatoid arthritis. Psychiatr Q 2020; 91: 53-64, DOI: 10.1007/s11126-019-09680-x.

30. Masood A, Salim B, Nasim A, et al. Are we missing the diagnosis of depression in patients with rheumatoid arthritis at a tertiary care facility? Pak J Med Sci 2017; 33: 300-305, DOI: 10.12669/pjms.332.11856.

31. Snaith RP. The Hospital Anxiety and Depression Scale. Health Qual Life Outcomes 2003; 1: 29, DOI: 10.1186/1477-7525-1-29.

32. Fransen J, Stucki G, van Riel P. Rheumatoid arthritis measures: Disease Activity Score (DAS), Disease Activity Score-28 (DAS28), Rapid Assessment of Disease Activity in Rheumatology (RADAR), and Rheumatoid Arthritis Disease Activity Index (RADAI). Arthritis Rheum 2003; 49: S214-224, DOI: 10.1002/ art.11407. 